rubella and doctors should set an example in eradicating this preventable disease.

AIDEen C Fogarty

Community Child Health Department,

St Edmund's Hospital,

Northampton NN1 4DS

\section{Making access to health care more equal}

SIR,-I have difficulty in understanding the costing in the paper by Messrs Gwyn Bevan and John Charlton (26 September, p 764). Table I refers to a mean expenditure by family practitioner committees on medical services per head of $£ 6.76$ in 1980-1.

In 1981 the gross expenditure on general medical services was $£ 16$ per head. ${ }^{1}$ Over $90 \%$ would be revenue. Moreover, general medical practitioners incur a far greater expenditure from pharmaceuticals_£23 per head.

A fairer comparison of the contribution of the family practitioner committee budget to total medical expenditure would be $£ 39$ per head per year compared with $£ 148$ per head for hospital services.

$\mathrm{J} J$ JONES

Department of Community Medicine,

Leicestershire Health Authority,

Leicester LE1 6TP

1 Office of Health Economics. Compendium of health service statistics. 6th ed. London: OHE, 1987: table 2.7(a).

SIR,-We are grateful for Dr Jones's letter, which has led us to identify errors in the data on which our paper (26 September, p 764) was based. The spending on general medical services was halved and the data on distances from target were for 1979-80, not 1980-1 (as we reported). In addition there were a few coding errors in data on both general medical services and distances from targets. Thus our observation that spending per head by Wiltshire and Somerset differed by nearly twofold was wrong; there was little difference between them in 1980-1. We apologise for these mistakes.

We have analysed differences in spending using correct data for 1980-1. The figure shows that these correct figures produce a similar pattern to those reported in the paper. There is still a weak positive but statistically significant correlation $(r=0 \cdot 27$; $p<0.02$ ) between the levels of spending on these two services. Thus the paper's argument about policies for making access to health care more equal remain valid.

Our mean figure for general medical services spending per head is $£ 13.20$, which is still lower than the $£ 16$ cited by Dr Jones. But the figure of

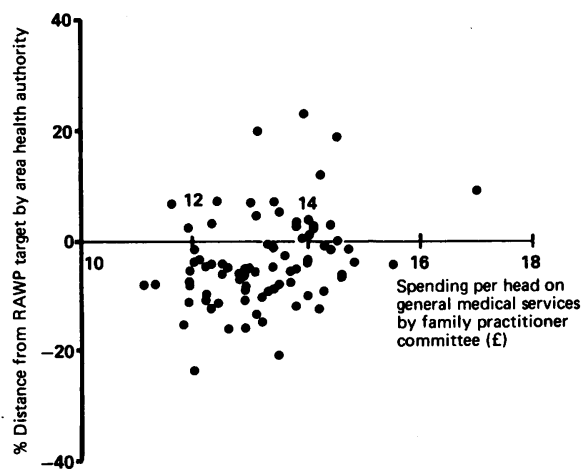

Distance from target and spending per head on general medical services by family practitioner committee.
$£ 16$ is for the calendar year 1981, and only one quarter of that year fell in the 1980-1 financial year. The figure given in the same table for spending in 1980 was $£ 13,{ }^{1}$ and our mean is consistent with the appropriate weighted average of those two years.

Dr Jones also suggests that a fairer comparison between the contribution of the family practitioner committee budget to total medical expenditure and hospital services would include spending on pharmaceuticals. Our concern was not to relate national average levels of spending on one service to the other but, following the Resource Allocation Working Party (RAWP), ${ }^{2}$ that of geographical distribution of resources in terms of fairness of access to health care-namely, that it is unbalanced to pursue a policy of equalising spending by health authorities without regard to the distribution of resources used by family practitioner committees. Therefore it seemed reasonable to focus on general medical services and exclude pharmaceutical expenditures. (Concern about equity in use of family practitioner committee medical resources would naturally include those expenditures.)

Despite errors in the data the main argument of our paper stands: we need to understand the relation between general medical services and health authority services if RAWP's objective is to be achieved.

GWYN BEvan

Department of Community Medicine,

JoHN ChARLTON

United Medical and Dental Schools of Guy's and St Thomas's, St Thomas's Hospital,

London SE1 7EH

1 Office of Health Economics. Compendium of health service statistics. 6th ed. London: OHE, 1987:table 2.7(a).

2 Department of Health and Social Security. Sharing resources for health in England. Report of the Resource Allocation Working Party. London: DHSS, 1976.

Extracorporeal shock wave lithotripsy: first 1000 cases at the London Stone Clinic

SIR,-In the paper by Mr G Das and others (10 October, p 891), of which I was an author, some criticism was levelled at the lithotripter centre at $\mathrm{St}$ Thomas's Hospital over its lower reported success rate and the overall patient management. As I now work in this unit and the London Stone Clinic no longer exists in its previous form I can comment further on these results.

Some of the differences may be explained by the differing criteria used to define success. The St Thomas's group reports that $44 \%$ of patients were totally stone free at three months, whereas we included patients with asymptomatic $(<2 \mathrm{~mm})$ fragments. These totalled 276 patients $(28 \%)$ at last follow up or 86 patients $(12 \%)$ at three months' follow up. One of the difficulties encountered in complete follow up within the National Health Service has been the lack of complete data supplied to St Thomas's by the referring hospitals and specialists. This may well skew the results as referring centres are more likely to report failures than successes.

Furthermore, the St Thomas's group has carefully analysed the position and size of the stones, with most being caliceal $(68 \%)$. This may reflect the fact that some referring clinicians treat the simpler stones by alternative methods such as percutaneous surgery and refer only the more complex ones.

As with any new technique, skills are being learnt, adapted, and refined, and in both units similar techniques are applied such as manipulation of upper ureteric stones back into the kidney before lithotripsy, using double $\mathrm{J}$ stents for stones $2-3 \mathrm{~cm}$ in diameter and preliminary percutaneous debulking for large stones. Therefore it would be untrue to suggest that these advanced endourological skills do not exist at the St Thomas's centre.

When patients have been accepted from other centres they are not discharged back to their referring hospitals, even with the inordinate pressure on beds at St Thomas's Hospital, unless the referring clinician has the necessary skill and equipment and is prepared to complete the treatment of residual stone fragments.

One major difference exists between the two units, in that a forced diuresis is not routinely used at St Thomas's. Whether this facilitates the passage of stone fragments remains uncertain and should perhaps be the subject of a controlled clinical trial.

\section{S FLETCHER}

Lithotripter Centre,

St Thomas's Hospital

London SE1 7EH

1 Palfrey ELH, Bultitude MI, Challah S, Pemberton J, Shuttleworth KED. Report on the first 1000 patients treated at Shuttleworth KED. Report on the first 1000 patients treated at B f Urol 1986;58:573-7.

\section{The ever interesting topic}

SIR,-Professor Rudolph Klein quoted some statistics in his article on the finances of the National Health Service ( 3 October, $p$ 843). As he himself remarked, "There are, of course, well known problems about all such calculations."

He quoted from the British Medical Association's report of 1970, which stated that "the National Health Service in this country is undoubtedly underfunded," and added, "All health services are always underfunded." $\mathrm{He}$ is, of course, correct, and everyone knows it. The government knows it too but for political reasons feels unable to admit it, sheltering behind its claim (which is true) that never before has the National Health Service had so much spent on it. Be that as it may, it is now half baked: the acutely and seriously ill are still well cared for, but anything less is frequently not done for months, sometimes years.

Major surgery is required. Management has been reorganised into administration (or is it the other way round?), and what is needed now is reorganisation of the clinical national health service, starting with the outright admission by the government that there has to be a limit on the money spent on it. Something along the following lines is the only practical solution.

Firstly, the government must take the country into its confidence and publicly admit that the dear, wonderful old National Health Service 40 years on is not safe in its hands, but that a trimmer, sleeker modern one would be. It would deal with "major" conditions (acute, lifesaving, etc, each to be specified) and would once again become the envy of the world. Secondly, alternative funding must be found for "routine" and minor conditions (each to be specified). As we all know, but some are reluctant to admit, this can come only from independent medical insurance. Thirdly, small new hospitals must be built (government or independently funded), whose use will be restricted to these routine cases and in which patients will be accommodated in six to eight bedded wards, with a rapid turnover. Premiums will thus be low and could be offset against tax (pensioners and the unemployed would not be required to pay them). There should be none of the unnecessary five star trappings that exist in most existing private hospitals, which, added to their increasing range of major surgery as the present National Health Service wilts, help to make their premiums too high for most people. 